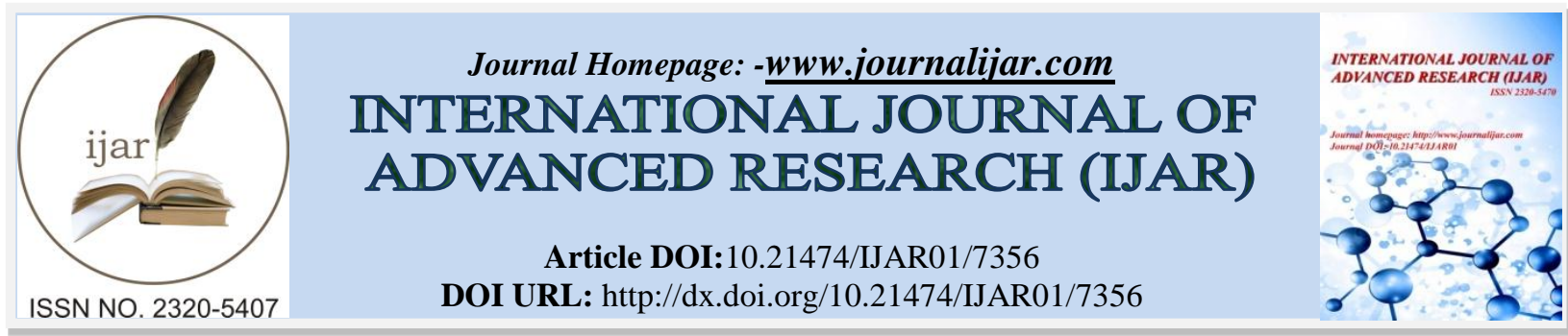

RESEARCH ARTICLE

\title{
SPECTROPHOTOMETRIC ESTIMATION OF PPM LEVEL OF SURFACTANTS IN COMMERCIALLY AVAILABLE TOOTHPASTES BY SOLVENT EXTRACTION.
}

R.P.Yadav, B.B.Bahule, V.T.Dangat and G.S.Lole.

Department of Chemistry, Nowrosjee Wadia College,Pune - 411001 Maharashtra,India.

\section{Manuscript Info}

Manuscript History

Received: 05 May 2018

Final Accepted: 07 June 2018

Published: July 2018

\section{Keywords:-}

Anionic surfactants, Methylene blue, Spectrophotometry.

\begin{abstract}
A spectrophotometric approach for the detection of surfactants in commercially available toothpastes has been proposed in this paper.

In this work, content of anionic surfactants in different samples of toothpastes was determined by spectrophotometrically. Method to estimate the amount of surfactants present in various samples of toothpastes, we have applied solvent extraction method combined with visible spectrophotometry. The formation of ionic pair between anionic surfactants (AS) and methylene blue (MB). Ionic-pair complex is determined by spectrophotometrically at the absorbance $660 \mathrm{~nm}$.

Parts per million levels of surfactants were estimated from commercially available toothpastes. The results of this study shows that the level of surfactants in the toothpastes studied follows the order,

Colgate strong-teeth $>$ Colgate Max-fresh $>$ Pepsodent $>$ Daber red Paste > Meswak
\end{abstract}

Copy Right, IJAR, 2018,. All rights reserved. 


\section{Introduction:-}

The term 'surfactant' indiacates that it is a substance that acts on surface. Substance that drastically lowers the surface tension of water even at low concentration are called 'surface active compounds' or surfactants ${ }^{1-3}$.

Most of the detergents contains anionic surfactants in major amount. Anionic surfactants present in various detergent samples. Anionic surfactants include alkyl benzene sulphonate, lauryl sulphate, dialkyl benzene sulphonaates, lignosulphonates, sodium do-decyl sulphates etc.

Anionic surfactants has been determined by spectrophotometric methods ${ }^{4-7}$. Various dyes have been used for estimation of anionic surfactants. Methylene blue and anionic surfactant form Ion-pair complex and absorbance of complex is determined by spectrophotometric method.

Anionic surfactant present in detergent samples is in very low concentrations and to estimate the low concentrations of surfactants various methods are employed ${ }^{8-10}$.

The objective of the present work is to estimate the amount of the surfactant present commercially available toothpastes at ppm level by colorimetric method.

From among the above methods to estimate the amount of the surfactants present in a given toothpastes, we have applied the solvent extraction method combined with visible spectrophotometry. The surfactant is extracted into an organic layer, which is collected. To absorbance of the colored complex is measured. This method is applicable to the commercial toothpest at ppm level.

In present study, the commercially available toothpaste samples are used in estimation of surfactants concentration in ppm level at $660 \mathrm{~nm}$.

\section{The commercially available toothpastes used in the present study are}

Colgate Strong Teeth

Meswak Complete Oral Care

Dabar Red Paste

Colgate Max Fresh

Pepsodent

\section{Experimental:-}

Chemicals: the ethyl acetate used was L.R. grade

\section{Procedure:-}

Purification of ethyl acetate: various grades of ethyl acetate are marketed. The anhydrous compound, BP 76-77 0C is of 99\% purity is inexpensive, and is suitable for most purpose. Ethyl alcohol and acetic acid are purified in the following manner. Mixture of 1 liter of ethyl acetate, $100 \mathrm{ml}$ of acetic anhydride, and 10 drops of conc. Sulphuric acid is refluxed for 3-4 hr. and then fractionated. The distillate is shaken with 20-30g of anhydrous potassium carbonate, filtered and redistilled. Methylene blue was from BDH chemicals India. Potassium dihydrogen phosphate and conc. Sulphuric acid were of LR grade from E.MERCK (India) Ltd.

Teepol was from glaxo lab (India) Bombay.

\section{Preparation Of Methylene Blue Reagent:-}

To prepare methylene blue, stock solution $0.1 \mathrm{~g}$ of methylene blue was dissolved in $100 \mathrm{ml}$ of distilled water. $30 \mathrm{ml}$ of stock solution of above solution was transferred to a $1000 \mathrm{ml}$ volumetric flask. $500 \mathrm{ml}$ of water, $6.8 \mathrm{ml}$ of conc. Sulphuric acid and $50 \mathrm{~g}$ of potassium dihydrogen phosphate di-hydrate were added to the solution. It was diluted to $100 \mathrm{ml}$.

\section{Prepration Of Surfactant Solutions:-}

Accurately weighed $100 \mathrm{mg}$ of the toothpest sample was dissolved in $1000 \mathrm{ml}$ of water. To prepare test solutions 10,20 , 
$30,40,50,60,70, \mathrm{ml}$ of the above stock solution was diluted to $100 \mathrm{ml}$. The resulting solution contained 10, 20, 30, 40, $50,60,70 \mathrm{ppm}$ of the surfactant.

\section{Solvent Extraction:-}

The toothpaste in known volume of the solution was extracted into an immiscible organic layer by solvent extraction. 83 $\mathrm{ml}$ of the surfactant solution was taken in an extraction column and mixed with $15 \mathrm{ml}$ of ethyl acetate. A stream of air was bubbled through the solution to extract the toothpaste into an organic solvent. The mixture was shaken for 30 minutes and then allowed to settle down. The aqueous layer was separated. The organic layer was collected and treated with $0.5 \mathrm{ml}$ of methylene blue reagent and its absorbance measured at $660 \mathrm{~nm}$ by Elico colorimeter.

\section{Optimum conditions:-}

The optimum conditions for solvent extraction were established by varying each one of the parameter and determining the optimum value. Thus, as mentioned above $30 \mathrm{~min}$ of extraction time was found to be adequate and longer time was unnecessary. Further, by varying the amount of methylene blue reagent it was observed that $0.5-0.75 \mathrm{ml}$ of the reagent gave maximum optical density. Similarly by varying the amount of ethyl acetate in the extraction column it was observed that $50 \mathrm{ml}$ ethyl acetate gave maximum optical density.

Sample 1:-Colgate Strong Teeth

Table 1.1:-Determination of $\lambda_{\max }$

\begin{tabular}{|c|c|c|}
\hline Solution in ppm & Wavelength / nm & Absorbance \\
\hline & & 0.07 \\
\hline 1 & 450 & 0.06 \\
\hline 2 & 470 & 0.07 \\
\hline 3 & 510 & 0.11 \\
\hline 4 & 520 & 0.14 \\
\hline 5 & 540 & 0.26 \\
\hline 6 & 570 & 0.48 \\
\hline 7 & 600 & 0.51 \\
\hline
\end{tabular}

Table 1.2:-Effect of solvent volume

\begin{tabular}{|c|c|c|}
\hline Sr. No. & mL of ethyl acetate added & Absorbance \\
\hline 1 & 10 & 0.01 \\
\hline 2 & 20 & 0.05 \\
\hline 3 & 30 & 0.09 \\
\hline 4 & 40 & 0.12 \\
\hline 5 & 50 & 0.14 \\
\hline 6 & 60 & 0.08 \\
\hline 7 & 70 & 0.04 \\
\hline 8 & 80 & 0.02 \\
\hline
\end{tabular}


Table 1.3:-Determination Of Absorbance For Volume Of Methylene Blue To Be Added

\begin{tabular}{|c|c|c|}
\hline Sr. No. & Methylene blue added $(\mathbf{m L})$ & Absorbance \\
\hline 1 & 0.2 & 0.40 \\
\hline 2 & 0.4 & 0.80 \\
\hline 3 & 0.6 & 0.45 \\
\hline 4 & 0.8 & 0.20 \\
\hline 5 & 1.0 & 0.10 \\
\hline
\end{tabular}

Table 1.4:-Determination of maximum absorbance of various concentrations

\begin{tabular}{|c|c|}
\hline Solution in ppm & Absorbance at 660 nm \\
\hline 10 & 0.42 \\
\hline 20 & 0.48 \\
\hline 30 & 0.57 \\
\hline 40 & 0.68 \\
\hline 50 & 0.76 \\
\hline 60 & 0.83 \\
\hline 70 & 0.88 \\
\hline 80 & 0.94 \\
\hline
\end{tabular}

Figure 1.1:-Effect of solvent volume

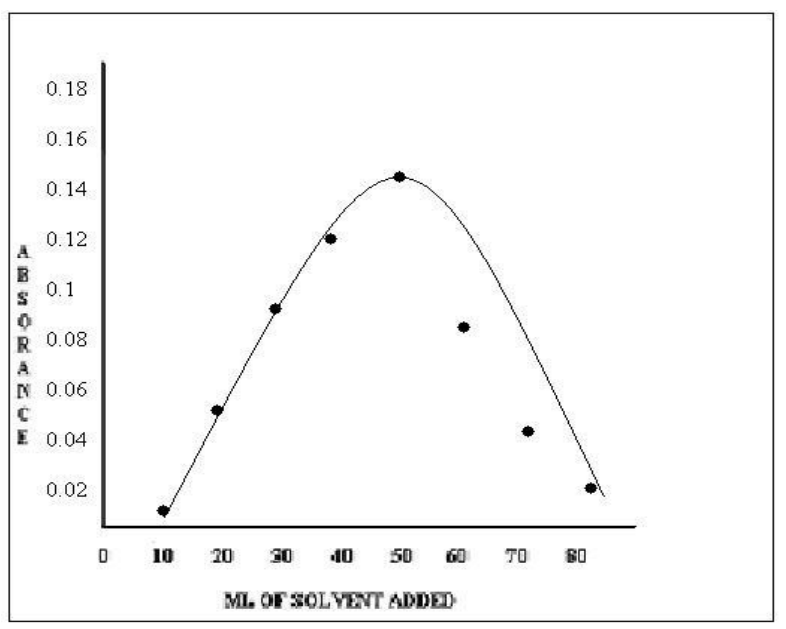

Figure 1.2:-Volume of methylene blue added

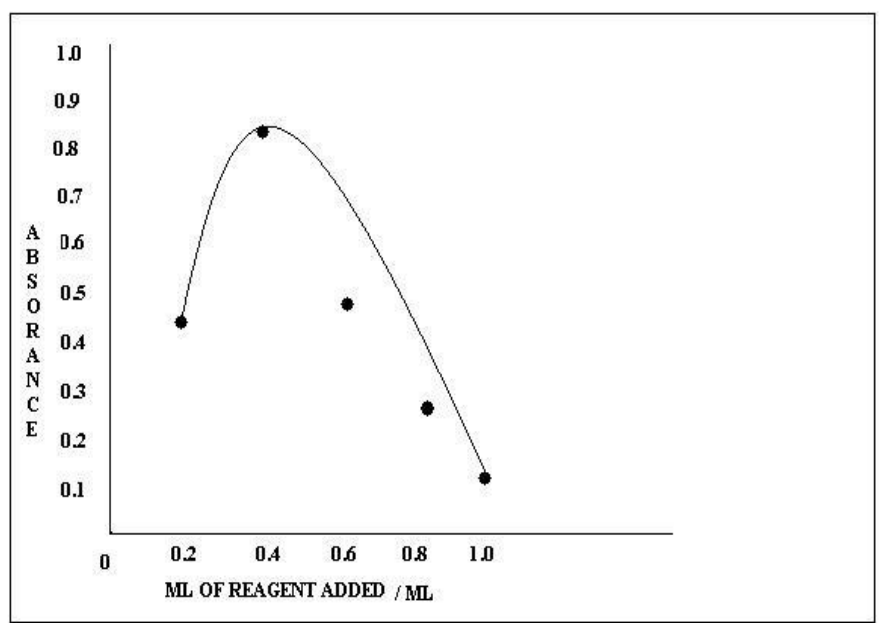

\section{Quantitative estimation:-}

All quantitative estimations of the toothpastes concentration were conducted under the condition of the optimum performance as explained above. The toothpest Colgate strong teeth taken as reference slandered. From stock solution an aliquot was pipetted out which contained $3 \mathrm{ppm}$ of the solution. The solution was subjected to solvent extraction and after treatment with methylene blue reagent; the optical density of the solvent layer was measured. The after solvent extraction, and treatment with the reagent, the optical density was measured in each case.

A plot of observed optical density vs concentration of the solution was drawn and was found to be satisfactorily linear.

\section{Other toothpastes:}

$100 \mathrm{mg}$ of the toothpastes sample was dissolved in $100 \mathrm{ml}$ distilled water; $10 \mathrm{ml}$ of aliquot was diluted to $100 \mathrm{ml}$. The diluted solution was subjected to solvent extraction as mentioned above. After the addition of methylene blue to the organic layer, its optical density was measured at $660 \mathrm{~nm}$. The amount of surfactant present in it was calculated from the calibration curve.

The above procedure was repeated for $0.002,0.003,0.004,0.005,0.006$, and $0.007 \%$ for all toothpastes. 
Table 2.1:-Maximum absorbance for Sample 2 ( Meswak complete oral care)

\begin{tabular}{|c|c|c|c|}
\hline Sr. NO. & Concentration & Absorbance & Concentration \\
\hline & of solution in & at $660 ~ \mathbf{~ m ~}$ & in ppm \\
\hline & \% & & 10 \\
\hline 2 & 0.001 & 0.39 & 20 \\
\hline 3 & 0.002 & 0.42 & 30 \\
\hline 4 & 0.003 & 0.44 & 40 \\
\hline 5 & 0.004 & 0.45 & 50 \\
\hline 6 & 0.005 & 0.48 & 60 \\
\hline 7 & 0.006 & 0.51 & 70 \\
\hline
\end{tabular}

Table 3.1:-Maximum absorbance for Sample 3 ( Dabar red paste )

\begin{tabular}{|c|c|c|c|}
\hline Sr. NO. & $\begin{array}{c}\text { Concentration } \\
\text { of solution in }\end{array}$ & Absorbance & Concentration \\
\hline & of surfactant & in ppm \\
\hline & 0.001 & & 10 \\
\hline 2 & 0.002 & 0.36 & 20 \\
\hline 3 & 0.003 & 0.39 & 30 \\
\hline 4 & 0.004 & 0.43 & 40 \\
\hline 5 & 0.005 & 0.49 & 50 \\
\hline 6 & 0.006 & 0.56 & 60 \\
\hline 7 & 0.007 & 0.61 & 70 \\
\hline 8 & 0.008 & 0.68 & 80 \\
\hline
\end{tabular}

Table 4.1:-Maximum absorbance for Sample 4 (Colgate max fresh)

\begin{tabular}{|c|c|c|c|}
\hline Sr. NO. & Concentration & Absorbance & Concentration \\
\hline & of solution in & at $660 ~ \mathbf{~ m ~}$ & surfactant \\
\hline 1 & \% & & 10 \\
\hline 2 & 0.001 & 0.53 & 20 \\
\hline 3 & 0.002 & 0.59 & 30 \\
\hline 4 & 0.003 & 0.64 & 40 \\
\hline 5 & 0.004 & 0.77 & 50 \\
\hline 6 & 0.005 & 0.78 & 60 \\
\hline 7 & 0.006 & 0.84 & 70 \\
\hline 8 & 0.007 & 0.87 & 80 \\
\hline
\end{tabular}

Table 5.1:-Maximum absorbance for Sample 5 ( Pepsodent )

\begin{tabular}{|c|c|c|c|}
\hline Sr. NO. & Concentration & Absorbance & Concentration \\
\hline & of solution in & at $660 ~ \mathbf{~ m ~}$ & surfactant \\
\hline 1 & \% & & 10 \\
\hline 2 & 0.001 & 0.52 & 20 \\
\hline 3 & 0.002 & 0.57 & 30 \\
\hline 4 & 0.003 & 0.65 & 40 \\
\hline 5 & 0.004 & 0.70 & 50 \\
\hline 6 & 0.005 & 0.73 & 60 \\
\hline 7 & 0.006 & 0.79 & 70 \\
\hline 8 & 0.007 & 0.83 & 80 \\
\hline
\end{tabular}


Results And Discussion:-

\begin{tabular}{|c|c|c|}
\hline Sr. No. & Toothpaste samples & Absorbance at 80 ppm concentration \\
\hline $\mathbf{1}$ & Colgate Strong Teeth & 0.94 \\
\hline $\mathbf{2}$ & Meswak Complete Oral Care & 0.55 \\
\hline $\mathbf{3}$ & Dabar Red Paste For Teeth \& Gums+ & 0.74 \\
\hline $\mathbf{4}$ & Colgate Max Fresh & 0.91 \\
\hline $\mathbf{5}$ & Pepsodent & 0.89 \\
\hline
\end{tabular}

Colgate Strong Teeth has higher absorbance and Meswak Complete Oral Care has lower absorbance at 80 ppm. This change is due to anionic surfactants present in Colgate Strong Teeth form strong complex with methylene blue dye than Meswak Complete Oral Care toothpaste and absorbance of all toothpastes samples are determined at 660 nm.

\section{Conclusion:-}

The effective concentration in the Toothpastes studied follows the following pattern :

\section{Colgate Strong-Teeh > Colgate-Max Fresh $>$ Pepsodent $>$ Daber Red $>$ Meswak}

This above order suggests that Colgate Strong Teeth toothpaste has better cleansing power than that of Meswak Complete Oral Care toothpaste.

As a volume of methylene blue added increases the optical density shift to higher value, this proves that added volume of methylene blue form colored complex with anionic surfactants present in all commercially available toothpaste samples and absorbance is measured at $660 \mathrm{~nm}$.

\section{Acknowledgement:-}

The authors area thankful to Principal Nowrosjee Wadia College, Pune for providing the necessary infrastructure and constant encouragement.

\section{References:-}

1. A.W.Adamson, Physical Chemistry of Surfaces, ( Interscience,New York), $2^{\text {nd }}$ edition,(1967)

2. Oscik, Adsorption, John Willey and Sons, New York, (1962)

3. G.M.Barrow, Physical Chemistry, $5^{\text {th }}$ edition, Tata McGraw-Hill Publications, (1992)

4. K.Yamamoto,K.Hiraiwa and Bunseki Kagaku, 43,(1994), 679

5. J.H.Jones,J.Assoc.Offic.Agr.Chemists, 26, (1945), 945

6. S.Chitikela, S.K.Dentel and H.E.Allen, Analyst(London), 120,(1995), 2001

7. L.N.Moskivin,D.N.Nikolaeva and N.V.Mikhailova,J.Anal.Chem,51,(1996),304

8. Glasstone Samuel, Textbook of Physical Chemistry, 2 nd edition, D.Ran Mostrand Co.Inc,New York, (19510, 1206

9. E.J.Welchar, Standard methods of chemical analysis, 6 th edition, Vol.3 (1975)

10. Masaki Koga, Yasushi Yamamichi, Yasuyo Nomoto, Maki Irie, Toshifumi Tanimura and Tetsutaro Yoshinaga, Analytical Sciences, Vol.15, (1999), 563-568 